\title{
Reply to the Letter to the Editor of J. Padulo et al. concerning "Calculation of corrected body height in idiopathic scoliosis: comparison of four methods" by M. Tyrakowski et al. (Eur Spine J, DOI 10.1007/s00586-014-3275-1)
}

\author{
Marcin Tyrakowski $\cdot$ Tomasz Kotwicki • \\ Jaroslaw Czubak $\cdot$ Kris Siemionow
}

Received: 18 April 2014/Revised: 7 June 2014/ Accepted: 7 June 2014/Published online: 21 June 2014

(C) The Author(s) 2014. This article is published with open access at Springerlink.com

Dear Editor,

We are glad that the authors of the Letter to the Editor found the topic of calculating the true body height in patients with scoliosis to be interesting and requiring research. With this response we thank the authors of the letter for pointing methodological inconsistencies of our study [1].

- We agree that other statistical methods should have been used [2-6], so we repeated the analysis using the intraclass correlation coefficient (ICC) and the median error for a single measurement (SEM), and obtained substantially similar results. There was an insufficient overall agreement between all the methods tested with the ICC of 0.66 and SEM of $5 \mathrm{~mm}$. Comparison of pairs of the methods is presented in Table 1 .

- In fact, we should have specified that order of the radiographs assessed by one researcher in three series of measurements at 1 week intervals as well as order of

M. Tyrakowski $(\square) \cdot$ J. Czubak

Department of Orthopaedics, Pediatric Orthopaedics and Traumatology, The Centre of Postgraduate Medical Education in Warsaw, ul. Konarskiego 13, 05-400 Otwock, Poland

e-mail: marcintyrak@gmail.com

M. Tyrakowski $\cdot$ K. Siemionow

Department of Orthopaedic Surgery, University of Illinois at Chicago, 835 South Wolcott Ave, Room E-270, Chicago,

Illinois 60612, United States

T. Kotwicki

Spine Disorders Unit, Department of Pediatric Orthopaedics and Traumatology, University of Medical Sciences in Poznan, ul. 28 Czerwca 1956 roku nr 135, 61-545 Poznan, Poland
Table 1 Comparison in pairs for the methods of calculating the loss of body height

\begin{tabular}{lll}
\hline Pairs of methods & ICC & SEM $(\mathrm{mm})$ \\
\hline Bjure vs. Kono & 0.23 & 9.5 \\
Stokes vs. Kono & 0.48 & 7.8 \\
Kono vs. measured & 0.66 & 6.3 \\
Bjure vs. Ylikoski & 0.38 & 5.1 \\
Ylikoski vs. Kono & 0.68 & 5.4 \\
Stokes vs. Ylikoski & 0.72 & 3.6 \\
Bjure vs. measured & 0.74 & 3.6 \\
Ylikoski vs. measured & 0.88 & 2.4 \\
Stokes vs. measured & 0.92 & 2.2 \\
Bjure vs. Stokes & 0.89 & 2.2 \\
\hline
\end{tabular}

the methods used in each session was different and random [randomization performed by use of Microsoft Office Excel 2007 (Microsoft, Redmond, WA, USA) with "RAND" function].

- After change of statistical methods, the ANOVA and Pearson's correlation addressed comments are not applicable.

- The same is valid for the last comment discussing the Pearson coefficient.

We think that these results add value to those published [1] while they are not changing conclusions of our study. Once again, many thanks for the help in proving our observations using appropriate statistics.

Conflict of interest None.

Open Access This article is distributed under the terms of the Creative Commons Attribution License which permits any use, distribution, and reproduction in any medium, provided the original author(s) and the source are credited. 


\section{References}

1. Tyrakowski M, Kotwicki T, Czubak J, Siemionow K (2014) Calculation of corrected body height in idiopathic scoliosis: comparison of four methods. Eur Spine J. doi:10.1007/s00586014-3275-1

2. Rankin G, Stokes M (1998) Reliability of assessment tools in rehabilitation: an illustration of appropriate statistical analyses. Clin Rehabil 12(3):187-199

3. Bland JM, Altman DG (1986) Statistical methods for assessing agreement between two methods of clinical measurement. Lancet 1(8476):307-310
4. Shrout PE, Fleiss JL (1979) Intraclass correlations: uses in assessing rater reliability. Psychol Bull 86:420-428

5. Streiner DL, Norman GR (2008) Health measurement scales a practical guide to their development and use, vol 4. Oxford University Press, Oxford

6. Kottner J, Audigé L, Brorson S, Donner A, Gajewski BJ, Hróbjartsson A, Roberts C, Shoukri M, Streiner DL (2011) Guidelines for reporting reliability and agreement studies (GRRAS) were proposed. J Clin Epidemiol 64(1):96-106 